\title{
What to Choose from Medical Treatment, Gallbladder Drainage or Cholecystectomy to Treat Acute Cholecystitis
}

\author{
Y. S. PEKER* AND B. TURKOGLU \\ Department of General Surgery, Gulhane Training and Research Hospital, University of Health Sciences, 06010, Ankara, \\ Turkey
}

Peker and Turkoglu: Management of acute cholecystitis

\begin{abstract}
The purpose of this study is to compare laparoscopic cholecystectomy with other treatment methods for acute cholecystitis at a university hospital. Treatments given to 197 patients with acute cholecystitis between 2016 and 2019 were examined. Three groups were set as first group of patients treated with interval cholecystectomy $(n=107)$, second group of patients treated with early cholecystectomy $(n=65)$ and third group of patients treated with gallbladder drainage $(n=25)$. Demographic characteristics, hospitalization duration, laboratory results and ultrasonography findings obtained from patient files were statistically analysed. Among the 197 acute cholecystitis patients there was no significant difference between the groups in terms of initial laboratory findings. There were significant differences in terms of the gallbladder wall thickness, pericholecystic fluid collection and age and hospitalization duration between the 3 groups. No mortality was observed in these patients while one patient developed bilioenteric fistula and was treated. After the treatment of acute cholecystitis, the treatment approach should be decided according to response to medical treatment, comorbidities, surgical risk of patient, and radiological findings independent of the initial laboratory findings. In conclusion, it is suggested that clinicians to assess pericholecystic fluid for early intervention of the patient and gallbladder thickness to decide about gallbladder drainage for the treatment of the patient along with patient's comorbidities.
\end{abstract}

Key words: Chemotherapy, stress cardiomyopathy, cancer

Acute cholecystitis (AC) is a frequently observed serious complication of gallbladder stones, and it usually occurs as a result of cystic duct obstruction and the inflammatory effect of lecithin found in bile. In addition to symptoms of abdominal pain, nausea and vomiting, sensitivity in the right subcostal region, moderate muscular rigidity and rebound tenderness may be observed. Among laboratory findings, an increase in C-reactive protein (CRP) levels and leucocytosis are noticeable. In some patients there might be an increase in pancreatic and hepatic enzymes due to obstruction of cystic duct or common bile duct by gallbladder stones. The easiest and most reliable method in the diagnosis of AC is hepatobiliary ultrasonography (USG). A gallbladder wall thickness of $>5 \mathrm{~mm}$ or pericholecystic fluid is supportive for the diagnosis. Besides, computerized tomography and magnetic resonance cholangiopancreaticography may also be used for radiological evaluation of gallbladder (fig. 1).
Some of AC cases, which have a significant place for acute abdomen approach indications progress severely and if not treated might lead to serious complications such as peritonitis and sepsis. The mortality rate was reported to be approximately $3 \%$ based on the severity of the disease and the general status of the patient ${ }^{[1-3]}$.

While various scales have been defined for the severity of the clinical picture, AC cases are usually classified according to the Tokyo Guideline 2018 (TG18) and treatment plans are made according to these guidelines ${ }^{[4-7]}$. Conducting early laparoscopic cholecystectomy (LC) in Grade I AC + Grade II stable patients and surgery planning after antibiotic treatment and fluid-electrolyte replacement in non-stable Grade II+ Grade III AC is a practice that is accepted by most centres. In addition to this, there are several articles that recommend application of alternative methods such as postponement of surgical treatment in high-risk $\mathrm{AC}$ 


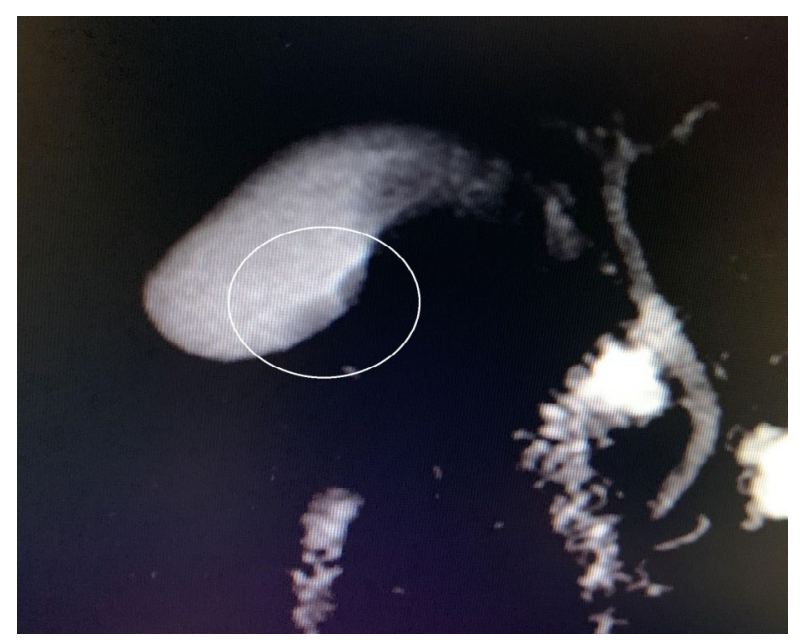

Fig. 1: Magnetic resonance cholangiopancreatographic image of gallbladder stone

Magnetic resonance cholangiopancreaticography in which the stones are viewed as hypointense. However, hepatopancreaticobiliary ultrasonography is needed for certain diagnosis

cases and gallbladder drainage (GBD) until the risky period is overcame ${ }^{[8-16]}$. In this retrospective study, it was aimed to assess the treatment methods applied to patients who were treated at a university hospital due to $\mathrm{AC}$ and indications of percutaneous gallbladder drainage/early surgical treatment.

\section{MATERIALS AND METHODS}

Patients 197 in number who received treatment for $\mathrm{AC}$ at the Gulhane Training and Research Hospital of University of Health Sciences during 2016-2019 were included in this study, while 1765 chronic cholecystitis patients who were treated by elective LC during the same period were excluded. Demographic characteristics, duration of hospitalization, initial laboratory results, gallbladder wall thickness and pericholecystic fluid findings in USG obtained from the files of the AC patients were recorded in an information form.

Cholecystectomies performed 4-6 w after medical treatment was defined as interval cholecystectomy (IC, group 1), while those that were performed within the $72 \mathrm{~h}$ after the onset of symptoms was defined as IC group 2. The standard clinical treatment protocol in $\mathrm{AC}$ involved intravenous fluid infusion, antibiotic/ analgesic treatment and interval LC. It was determined that interval LC was performed on the patients that responded positively to medical treatment according to laboratory results and radiological findings in the first $72 \mathrm{~h}$, early LC or conventional cholecystectomy was performed on patients who did not respond to medical treatment but had low surgical risk and the GBD procedure was performed on patients with high surgical risk or comorbidities.

The indications for GBD were determined as advanced age and comorbidities as oncological disease, chronic pulmonary disease, liver dysfunction and coagulopathy. GBD was determined to be performed as percutaneous transhepatic/transperitoneal or ERCP-guided transpapillary drainage, and $8 \mathrm{Fr}$ silicone catheters were used. During the procedures, short-term sedation was applied to the patients with midazolam or fentanyl. In all patients whom GBD was performed, routine control tubography was applied just after the procedure and on the $21^{\text {st }} \mathrm{d}$ of the procedure and the position of the catheter and the status of the gallbladder were imaged. The catheter was removed after the normalization of laboratory results and radiological findings with sufficient drainage of gall bladder around $3 \mathrm{w}$ of catheter placement and patient was scheduled for interval cholecystectomy.

The patient data were analysed by uploading onto the SPSS v25 software. The statistical analysis was carried out by using the non-parametric Kruskal-Wallis test, $\mathrm{p}<0.05$ values calculated in a $95 \%$ confidence interval were accepted as significant.

\section{RESULTS AND DISCUSSION}

The AC ratio among all cholecystitis cases that were treated in the 3 y period covered by the study was $10 \%$. According to the assessment made based on TG18, 121 (61\%) of the AC cases were Grade I, while 76 (39\%) were Grade II or Grade III. It was determined to perform IC on 107 (54\%) Group 1 patients who initially received the medical treatment protocol and their infection were taken under control, 65 (33\%) Group 2 patients who did not sufficiently respond to medical treatment received early cholecystectomy, and 25 (13\%) Group 3 patients who had severe comorbidities and assessed to have high surgical risk received GBD treatment.

Among the AC patients, 83 (42\%) were male, 114 $(58 \%)$ were female with a mean age of $57.7 \mathrm{y}$. In comparison to the patients who were treated with interval cholecystectomy and $\mathrm{GBD}$, the mean age in the early cholecystectomy patient group $(n=65)$ was $53.6 \mathrm{y}$, whereas their difference to the other groups was statistically significant $(\mathrm{p}=0.032) \quad$ (Table 1). Among the 65 patients who were treated with early cholecystectomy, conventional cholecystectomy was preferred in 8 patients $(12 \%)$, while in 57 patients (88\%), operation was started as LC, and there was 
conversion to conventional cholecystectomy among 19 (33\%) of these patients. Among the 25 patients with GBD indication, $10(40 \%)$ received percutaneous transhepatic/transperitoneal and $15(60 \%)$ received ERCP-guided trans-papillary GBD. Seven (28 \%) patients who received GBD treatment later received cholecystectomy. One patient (4\%) who received cholecystectomy firstly received percutaneous GBD, and due to unsuccessful drainage, ERCP-guided GBD was applied lately. Finally cholecystectomy was applied to this patient 1 mo after ERCP. Seventeen (68\%) patients who were subjected to GBD were discharged without cholecystectomy to make a decision for surgery later.

The mean hospitalization duration of the patients was $7.81 \mathrm{~d}$ (Table 1). The mean duration of hospitalization was $7.23 \mathrm{~d}$ in the IC group, $8.09 \mathrm{~d}$ in the early cholecystectomy group and $11.25 \mathrm{~d}$ in the GBD group and the difference was statistically significant for GBD group ( $\mathrm{p}=0.029$, Table 1$)$. The mean haematological parameters were, WBC- $14.36 \times 1000 / \mathrm{mm}^{3}$, CRP- 124.80 $\mathrm{mg} / \mathrm{l}$, PLT- $269 / \mu 1$, INR- 1.25 , total bilirubin- $1.39 \mathrm{mg} /$ $\mathrm{dl}$ and serum amylase: $84.97 \mathrm{U} / 1$ (Table 1). The mean gallbladder wall thickness of all patients in the sample was $5.26 \mathrm{~mm}$ (Table 1). USG examination revealed pericholecystic fluid in 97 (49\%) patients, whereas 46 patients $(47 \%)$ had minimal and 50 patients $(52 \%)$ had moderate levels of fluid (Table 1). In one patient (1\%), bileperitonitis in relation to gallbladderperforation was detected and emergency cholecystectomy was performed. The gallbladder wall was thinner in the patient group that had GBD in comparison to the other groups, the presence of pericholecystic fluid collection was lower in the interval LC group in comparison to the other groups and these differences were statistically significant $(\mathrm{p}=0.001$ and $\mathrm{p}=0.047$, respectively,
Table 1). While no mortality was seen in patients, it was observed that one patient developed bilioenteric fistula 2 mo after being discharged and was treated. The other patients were discharged without complications.

The prevalence of cholecystitis in the community is around $20 \%$, which increases with age. The treatment for cholecystitis is cholecystectomy and LC is the gold standard treatment method due to its advantages over conventional cholecystectomy such as low morbidity and complication rate, short duration of hospitalization and low postoperative pain. AC cases, which constitute approximately $10 \%$ of all cholecystitis cases, are risky in terms of $\mathrm{LC}^{[1,8,17,18]}$. For this reason, the timing and type of cholecystectomy in AC treatment are questionable and surgeons have different practices in this field. As the laparoscopy experiences of general surgeons have increased and safer devices working with plasma kinetic energy have come into use in the last 3 decades, the rate of usage of early LC in AC treatment has increased rapidly ${ }^{[3,19-23]}$. However, in some patients, the presence of severe inflammation at and around the gallbladder, intense adhesions, uncontrollable intraoperative bleeding and high risk of biliary tract injury increases the conversion and complication rates (figs. 2 and 3). It is recommended to prefer conventional cholecystectomy instead of LC in these patients or to perform GBD, which is an alternative method in patients who cannot receive surgery due to these high risks $^{[2,10-12,14,16,24-29]}$.

The conversion rates of LC, which are very low $(2-5 \%)$ in chronic cholecystitis cases vary in the range of $6-35 \%$ in early LC operations performed due to $\mathrm{AC}^{[3,17,29,30]}$. In order to protect the patient from complications and risks and also to reduce the conversion rates, it seems logical to initially take the inflammation at the gallbladder and surrounding tissues under control

\section{TABLE 1: FINDINGS OF ACUTE CHOLECYSTITIS PATIENTS}

\begin{tabular}{|c|c|c|c|c|c|}
\hline Parameters & $\begin{array}{c}\text { IC } \\
(n=107)(54 \%)\end{array}$ & $\begin{array}{c}\text { EC } \\
(n=65)(33 \%)\end{array}$ & $\begin{array}{c}\text { GBD } \\
(n=25)(13 \%)\end{array}$ & $\begin{array}{c}\text { Total } \\
(n=197)\end{array}$ & $\mathrm{p}$ value \\
\hline Hospitalization duration (d) & 7.23 & 8.09 & 11.25 & 7.81 & $p=0.029$ \\
\hline Age $(y)$ & 59.24 & 53.68 & 59.2 & 57.71 & $p=0.032$ \\
\hline WBC $\left(\times 1000 / \mathrm{mm}^{3}\right)$ & 14.170 & 15.08 & 12.81 & 14.36 & $p=0.309$ \\
\hline CRP (mg/l) & 121.80 & 123.17 & 132.30 & 124.80 & $p=0.656$ \\
\hline $\operatorname{PLT}(/ \mu l)$ & 269.13 & 273.83 & 251.63 & 269.03 & $p=0.670$ \\
\hline INR & 1.16 & 1.27 & 1.48 & 1.25 & $p=0.420$ \\
\hline Total bilirubin (mg/dl) & 1.43 & 1.11 & 1.85 & 1.39 & $p=0.159$ \\
\hline Amilase (U/l) & 68.41 & 51.22 & 173.56 & 84.97 & $p=0.758$ \\
\hline Gallbladder wall thickness (mm) & 5.34 & 5.43 & 4.97 & 5.26 & $p=0.047$ \\
\hline Pericholecystic fluid presence & $40(37 \%)$ & $41(63 \%)$ & $16(64 \%)$ & 107 (54 \%) & $p=0.001$ \\
\hline
\end{tabular}

$\mathrm{IC}$ is group 1 patients with interval cholecystectomy, EC is group 2 with early cholecystectomy and GBD is group 3 patients who underwent gallblader drainage. WBC is white blood cells, CRP is C-reactive protein, LPT is platelets and INR is international normslized ratio 


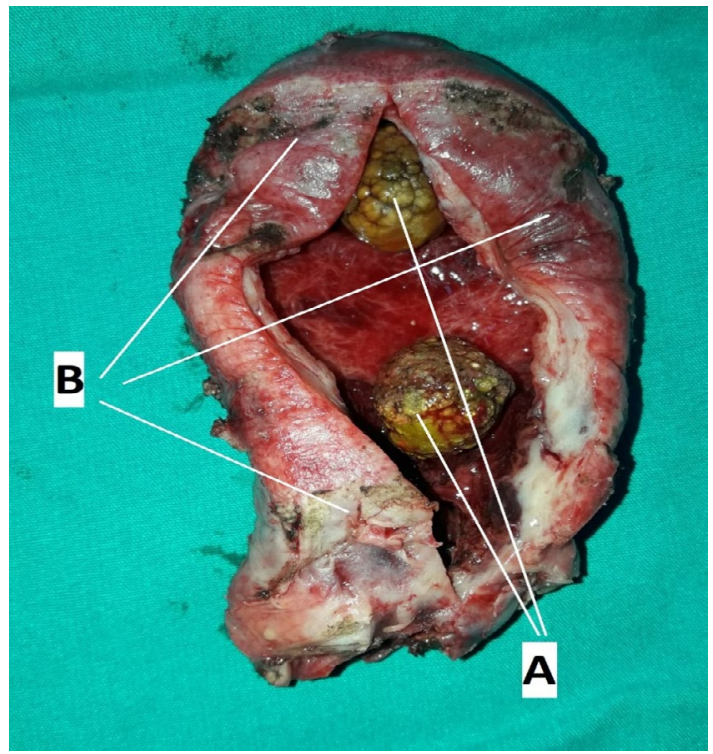

Fig. 2: Acute cholecystitis specimen resected by laparoscopic cholecystectomy

A. Two stones are seen in the gallbladder, B. severe inflammation of gallbladder with necrosis and fibrin

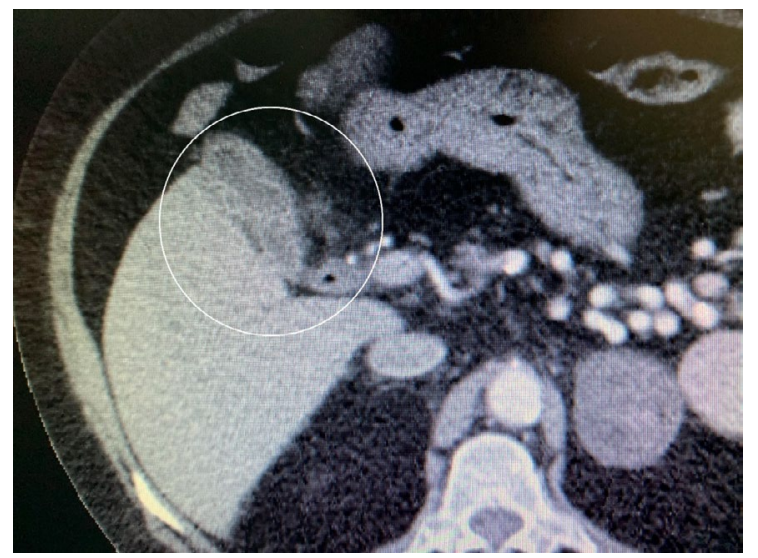

Fig. 3: Computerized tomographic view of gallbladder Severely inflammed gallbladder with increased wall thickness and minimal heterogenity around gallbladder

and then perform surgery later under appropriate conditions. While the conversion rates at the patients that did not sufficiently respond to medical treatment and received early LC in this study was very high $(33 \%)$, it was seen that interval LC that was performed in $54 \%$ of all $\mathrm{AC}$ patients following medical treatment was carried out with a conversion rate of $2 \%$, which agreed with the literature. Although findings in this study for conversion at early LC for AC did not support many literature reports, several authors have provided lower conversion rates for early $\mathrm{LC}$ at treatment of $\mathrm{AC}$, and they have stated that early LC needs to be the first option in AC treatment ${ }^{[19,22,31-35]}$.

Surgical risk may be very high in some AC patients due to serious medical problems such as advanced age, oncological disease, chronic pulmonary and liver disease, coagulopathy or surgery may have high complication risk due to severe gallbladder inflammation. There are several studies which have reported that it is a good alternative to provide medical treatment and GBD for these patients and postpone the decision for surgery for later ${ }^{[24-26,36,37]}$.

In this study, it was determined that $25(13 \%)$ of the patients could not be operated due to severe medical problems and were monitored with medical treatment and by applying GBD catheters, late cholecystectomy could be performed on 7 (28\%) of these patients, and for others, the decision of surgery was postponed, the patients were discharged without cholecystectomy following medical treatment and GBD.

GBD methods involve a temporary procedure that aims the drainage of infected bile for generally $3 \mathrm{w}$ in AC cases for patients with comorbidities or high surgical risk. Due to easiness of application, many centres prefer to apply percutaneous transhepatic/transperitoneal catheters $^{[2,11,24-26,38]}$. However, as this method provides drainage by injuring liver and perforating the gallbladder wall, it may lead to bile leakage, skin irritation, increase at pericholecystic adhesions and cause difficulty of dissection during cholecystectomy that is planned for later. On the other hand, in the ERCPguided GBD technique, as the procedure is performed from the endoscopic trans-papillary route, the integrity of the gallbladder wall is not disrupted and this did not have an effect that increases pericholecystic adhesions. Another advantage of it is that if there are materials such as bile stones and debris in the extrahepatic bile ducts, it allows drainage of these also during the procedure ${ }^{[27,28,36,39-42]}$. This method is preferred more at centres with the appropriate technical infrastructure and experienced endoscopists. For this reason, ERCPguided GBD was preferred more at this study centre. As an alternative to these temporary GBD techniques, there are also permanent GBD techniques. Some researchers have reported that performing permanent transmural or trans-choledochal GBD with plastic or metal stents placed from the stomach or duodenum with endoUSG guidance provides better results in terms of patient comfort $^{[8,10,28,39,43]}$.

However, GBD has disadvantages as it has advantages described above. It is observed in this study that as these patients had serious medical problems and the GBD catheters were left in place for a long time, the mean duration of hospitalization for these patients was significantly longer than other groups $(11.25 \mathrm{~d}, \mathrm{p}=0.029$, 
Table 1). This might lead to hospital infections and also long term invasive catheterization might cause sepsis leading to septic shock. Also bile leakage as described above is also one of the complications. Duodenal and common bile duct perforation is also a severe complication of ERCP applied for GBD. Beyond these, uncontrolled bleeding is one of the complications that should be considered due to transhepatic catheterization. Even though there were no cases of perforation and bleeding complication resulting from GBD, these complications should still be kept in mind.

Gallbladder wall thickness and pericholecystic fluid collection are considered to be one of the most significant radiological findings of $\mathrm{AC}^{[44-47]}$. There are studies, which have reported that the rate of gangrenous and emphysematous cholecystitis is higher in cases with pericholecystic fluid/abscess collection and a gallbladder wall thickness of higher than $5 \mathrm{~mm}^{[48-51]}$. In the assessment of the groups in terms of the gallbladder wall thickness, GBD group had significantly lower thickness $(p=0.047)$ and when the pericholecystic fluid collection was assessed, the IC group had significantly less patients with collection $(\mathrm{p}=0.001)$. Also no significant difference among the patient groups in terms of the initial laboratory findings even among CRP and WBC values (Table 1) was detected.

All the results discussed above indicate to build up a more clear approach modality for the treatment of AC. Because the patients involved in this study has no mortality and very low morbidity with $0.5 \%$, the treatment approach can be assessed as a successful approach. First of all according to current data, medical treatment with antibiotics and antiinflammatory drugs with hydration should be introduced to all AC patients. The debate begins at this point; when to operate? It is suggested that IC if the patient responded well to the medical treatment. Also having no pericholecystic fluid is an important indicator for interval laparoscopy as per this study's findings, the presence of pericholecystic fluid should guide the clinician for early intervention of the patient as cholecystectomy or GBD. If there is no sufficient response to the medical treatment again early intervention as cholecystectomy or GBD should be planned for the patient independent of the initial laboratory results. If patient has comorbidities described above or has high risk for operation and in addition to these, has thinner gallbladder wall $(<5 \mathrm{~mm})$, GBD may be considered instead of early cholecystectomy. If patient doesn't have the comorbidities described above and has acceptable risk for operation and in addition, as a new data, increased gallbladder wall thickness, early cholecystectomy may be considered instead of GBD. But still, pericholecystic fluid, gallbladder wall thickness, comorbidities and surgical risks should be all assessed as a combination to decide about early cholecystectomy or GBD for patients without sufficient respond to medical treatment for acute cholecystectomy management.

In conclusion, the outcomes of the study suggested to have a more certain decision about applying which invasive procedure to the $\mathrm{AC}$ patients who did not respond to medical treatment. Pericholecystic fluid should guide the clinician for early intervention of the patient and thin gallbladder wall may guide the clinician to GBD instead of early cholecystectomy. In addition to gallbladder wall thickness and pericholecystic fluid, independent of the patient's initial laboratory findings, comorbidities of the patient and surgical risk of the patient should also be considered for the final decision of GBD or early cholecystectomy for management of AC.

\section{Conflict of interest:}

All authors report no conflicts of interest in this work.

\section{REFERENCES}

1. Lee SO, Yim SK. Management of Acute Cholecystitis. Korean J Gastroenterol 2018;71: 264-8.

2. Sanaiha Y, Juo YY, Rudasill SE Jaman R, Sareh S, Virgilo $\mathrm{C}$, et al. Percutaneous cholecystostomy for grade III acute cholecystitis is associated with worse outcomes. Am J Surg 2019;S0002-9610:31539-9.

3. Pal I, Bhatti U, Bari J. Changing trends in surgical management for acute cholecystitis, in light of Tokyo guidelines - 14 year experience. J Pak Med Assoc 2019;69:1505-8.

4. Wakabayashi G, Iwashita Y, Hibi T, Takata T, Strasberg SM, Asbun HJ, et al. Tokyo Guidelines 2018: surgical management of acute cholecystitis: safe steps in laparoscopic cholecystectomy for acute cholecystitis. J Hepatobiliary Pancreat Sci 2018;25:73-86.

5. Yokoe M, Hata J, Takada T, Strasberg SM, AsbunHJ, Wakabayashi G, et al. Tokyo Guidelines 2018: diagnostic criteria and severity grading of acute cholecystitis (with videos). J Hepatobiliary Pancreat Sci 2018;41-54.

6. Madni TD, Leshikar DE, Minshall CT, Nakonezny PA, Cornelius CC, Imran JB, et al. The Parkland grading scale for cholecystitis. Am J Surg 2018;215:625-30.

7. Vera K, Pei KY, Schuster KM, Davis KA. Validation of a new American Association for the Surgery of Trauma (AAST) anatomic severity grading system for acute cholecystitis. J Trauma Acute Care Surg 2018;84:650-54.

8. Teoh AYB. Outcomes and limitations in EUS-guided gallbladder drainage. Endosc Ultrasound 2019;8:S40-S43.

9. Mohan BP, Khan SR, Trakroo S, Ponnada S, Jayaraj M, Asokkumar R, et al. Endoscopic ultrasound-guided gallbladder drainage, trans papillary drainage, or percutaneous drainage in 
high risk acute cholecystitis patients: a systematic review and comparative meta-analysis. Endoscopy 2020;52:96-106.

10. James TW, Baron TH. EUS-guided gallbladder drainage: A review of current practices and procedures. Endosc Ultrasound 2019;8:S28-S34.

11. Dvorak P, Hoffmann P, Renc O, Dusek T, Rejchrt S, Slezak $\mathrm{O}$, et al. Percutaneous cholecystostomy in the management of acute cholecystitis 10 years of experience. Wideochir Inne Tech Maloinwazyjne 2019;14:516-25.

12. Hjaltadottir $\mathrm{K}$, Haraldsdottir $\mathrm{KH}$, Hannesson $\mathrm{PH}$, Moller $\mathrm{PH}$. Percutaneous cholecystostomy as treatment for acute cholecystitis at Landspitali University Hospital 2010-2016. Laeknabladid 2019;105:171-6.

13. Jia B, Liu K, Tan L, Jin Z, Liu Y. Percutaneous transhepatic gallbladder drainmage combined with laparoscopic cholecystectomy versus emergency laparoscopic cholecystectomy in acute complicated cholecystitis. Am Surg 2018;84:438-42.

14. Colonna AL, Griffiths TM, Robison DC, Enniss TM, Young JB, McCurum ML, et al. Cholecystostomy: Are we using it correctly? Am J Surg 2019;217:1010-15.

15. Schlottmann F, Gaber C, Strassle PD, Patti MG, Charles AG. Cholecystectomy vs. cholecystostomy for the management of acute cholecystitis in elderly patients. J Gastrointest Surg 2019;23:503-9.

16. Janssen ERI, Hendriks $T$, Natroshvili $T$, Bremers AJA. Retrospective Analysis of Non-Surgical Treatment of Acute Cholecystitis. Surg Infect 2020;21:428-32.

17. Mou D, Tesfasilassie T, Hirji S, Ashley SW. Advances in the management of acute cholecystitis. Ann Gastroenterol Surg 2019;3:247-53.

18. Wu PS, Chou CK, Hsieh YC, Chen CK, Lin YT, Huang $\mathrm{YH}$, et al. Antibiotic use in patients with acute cholecystitis after percutaneous cholecystostomy. J Chin Med Assoc 2020;83:134-40.

19. Song GM, Bian W, Zeng XT, Zhou JG, Luo YQ, Tian X. Laparoscopic cholecystectomy for acute cholecystitis: early or delayed?: Evidence from a systematic review of discordant meta-analyses. Medicine 2016;95:e3835.

20. Borzellino G, Khuri S, Pisano M, Mansour S, Allievi N, Ansoloni L, et al. Timing of early laparoscopic cholecystectomy for acute calculous cholecystitis revised: Protocol of a systematic review and meta-analysis of results. World J Emerg Surg 2020;15:1.

21. Lin D, Wu S, Fan Y, Ke C. Comparison of laparoscopic cholecystectomy and delayed laparoscopic cholecystectomy in aged acute calculous cholecystitis: a cohort study. Surg Endosc 2020;34:2994-3001.

22. Cao AM, Eslick GD, Cox MR. Early laparoscopic cholecystectomy is superior to delayed acute cholecystitis: a meta-analysis of case-control studies. Surg Endosc 2016;30:1172-82.

23. Busto Bea V, Caro Patón A, Aller Dela Fuente R, Gonzalez Sagrado M, Garcia-Alonso FJ, Perez-Miranda Castillo M, et al. Acute calculous cholecystitis: a real-life management study in a tertiary teaching hospital. Rev Esp Enferm Dig 2019;111:667-71.

24. Gupta P, Maralakunte M, Rathee S, Samanta J, Sharma V, Mandavdhare $\mathrm{H}$, et al. Percutaneous transhepatic biliary drainage in patients at higher risk for adverse events: experience from a tertiary care referral center. Abdom Radiol 2019;1-7.

25. Garcés-Albir M, Martín-Gorgojo V, Perdomo R, MolinaRodriguez JL, Munoz-Former e, Dorcaratto D, et al. Acute cholecystitis in elderly and high-risk surgical patients: is percutaneous cholecystostomy preferable to emergency cholecystectomy? J Gastrointest Surg 2019;1-8.

26. Morales-Maza J, Rodríguez-Quintero JH, Santes O, HernandezVillegas AC, Clemente-Gutierrez U, Sanches Morales GE, et al. Percutaneous cholecystostomy as treatment for acute cholecystitis: What has happened over the last five years? A literature review. Rev Gastroenterol Mex 2019;84:482-91.

27. Sagami R, Hayasaka K, Nishikiori H, Harada H, Amano Y. Current Status in the Treatment of Acute Cholecystitis Patients Receiving Antithrombotic Therapy: Is Endoscopic Drainage Feasible?- A Systematic Review. Clin Endosc 2020;53:176-88.

28. Ogura T, Higuchi K. Endoscopic ultrasound-guided gallbladder drainage: Current status and future prospects. Dig Endosc 2019;31:55-64.

29. Philip Rothman J, Burcharth J, Pommergaard HC, Viereck S, Rosenberg J. Preoperative Risk Factors for Conversion of Laparoscopic Cholecystectomy to Open Surgery - A Systematic Review and Meta-Analysis of Observational Studies. Dig Surg 2016;33:414-23.

30. Panni RZ, Strasberg SM. Preoperative predictors of conversion as indicators of local inflammation in acute cholecystitis: strategies for future studies to develop quantitative predictors. J Hepatobiliary Pancreat Sci 2018;25:101-8.

31. Cockcroft A, Verrico E, Xing S, Westerman S, Jung M, Sullivan $\mathrm{R}$, et al. Hospital Enforcement of Early Cholecystectomy for Acute Cholecystitis. Am Surg 2019;85:858-60.

32. Paudel R. Is it safe to perform laparoscopic cholecystectomy for acute calculus cholecystitis within 7 days following symptom onset? JNMA J Nepal Med Assoc 2018;56:945-8.

33. Zhong FP, Wang K, Tan XQ, Nie J, Huang WF, Wang XF. The optimal timing of laparoscopic cholecystectomy in patients with mild gallstone pancreatitis: A meta-analysis. Medicine 2019;98:e17429.

34. Loozen CS, van Ramshorst B, van Santvoort HC, Boerma D. Early Cholecystectomy for Acute Cholecystitis in the Elderly Population: A Systematic Review and Meta-Analysis. Dig Surg 2017;34:371-9.

35. Jarrar MS, Chouchène I, Fadhl H, Ghrissi R, Elghali A, Ferhi $\mathrm{F}$, et al. Early versus delayed laparoscopic cholecystectomy for lithiasic acute cholecystitis during emergency admissions. Results of a monocentric experience and review of the literature. Tunis Med 2016;94:519-24.

36. Rerknimitr R, Pham KC. Practical Approaches for High-Risk Surgical Patients with Acute Cholecystitis: The Percutaneous Approach versus Endoscopic Alternatives. Clin Endosc 2020.

37. Choi JW, Park SH, Choi SY, Kim HS, Kim TH. Comparison of clinical result between early laparoscopic cholecystectomy and delayed laparoscopic cholecystectomy after percutaneous transhepatic gallbladder drainage for patients with complicated acute cholecystitis. Korean J Hepatobiliary Pancreat Surg 2012;16:147-53.

38. Abe K, Suzuki K, Yahagi M, Murata T, Sako H, Ishii Y. The Efficacy of PTGBD for Acute Cholecystitis Based on the Tokyo Guidelines 2018. World J Surg 2019;43:2789-96.

39. Salerno R, Davies SEC, Mezzina N, Ardizzone S. Comprehensive review on EUS- guided biliary drainage. World J Gastrointest Endosc 2019;11:354-64.

40. Higa JT, Irani SS. Endoscopic Methods for Gallbladder Drainage. Curr Treat Options Gastroenterol 2019;17:357-66.

41. Torres Yuste R, Garcia-Alonso FJ, Sanchez-Ocana R, Roman MC, Herrero IP, Carbajo AY, et al. Safety and efficacy of endoscopic ultrasound-guided gallbladder drainage combined 
with endoscopic retrograde cholangiopancreatography in the same session. Dig Endosc 2019;32:608-15

42. Kaura K, Bazerbachi F, Sawas T, Levy MJ, Martin JA, Srorm AC, et al. Surgical outcomes of ERCP-guided transpapillary gallbladder drainage versus percutaneous cholecystostomy as bridging therapies for acute cholecystitis followed by interval cholecystectomy. HPB 2019;S1365-182X:32272-5.

43. Law R, Baron TH. Endoscopic Ultrasound-Guided Gallbladder Drainage. Gastrointest Endosc Clin N Am 2018;28:187-15.

44. Sureka B, Rastogi A, Mukund A, Thapar S, Bhadoria AS, Chattopadhyay TK. Gangrenous cholecystitis: Analysis of imaging findings in histopathologically confirmed cases. Indian J Radiol Imaging 2018;28:49-54.

45. Kim KH, Kim SJ, Lee SC, Lee SK. Risk assessment scales and predictors for simple versus severe cholecystitis in performing laparoscopic cholecystectomy. Asian J Surg 2017;40:367-74.

46. Shirah BH, Shirah HA, Saleem MA, Chughtai MA, Elraghi MA, Shams ME. Predictive factors for gangrene complication in acute calculous cholecystitis. Ann Hepatobiliary Pancreat Surg 2019;23:228-33.

47. Real-Noval H, Fernández-Fernández J, Soler-Dorda G. Predicting factors for the diagnosis of gangrene acute cholecystitis. Cir Cir 2019;87:443-9.

48. Wu B, Buddensick TJ, Ferdosi H, Narducci DM, Sautter A,
Setiawan L, et al. Predicting gangrenous cholecystitis. HPB 2014;16:801-6.

49. Oppenheimer DC, Rubens DJ. Sonography of Acute Cholecystitis and Its Mimics. Radiol Clin North Am 2019;57:535-48.

50. Yeh DD, Cropano C, Fagenholz P, Narducci DM, Sautter A, Setiawan L, et al. Gangrenous cholecystitis: deceiving ultrasounds, significant delay in surgical consult, and increased postoperative morbidity! J Trauma Acute Care Surg 2015;79:812-6.

51. Uemura S, Higuchi R, Yazawa T, Izumo W, Sugishita T, Morita $\mathrm{S}$, et al. Impact of transient hepatic attenuation differences on computed tomography scans in the diagnosis of acute gangrenous cholecystitis. J Hepatobiliary Pancreat Sci 2019;26:348-53..

This is an open access article distributed under the terms of the Creative Commons Attribution-NonCommercial-ShareAlike 3.0 License, which allows others to remix, tweak, and build upon the work non-commercially, as long as the author is credited and the new creations are licensed under the identical terms

This article was originally published in a special issue, "Biomedical Research in Healthcare Setting" Indian J Pharm Sci 2020:82(2)Spl issue5;41-47 